\title{
Ignition Delay Time Correlation of Fuel Blends based on Livengood-Wu Description
}

\author{
Fethi Khaled ${ }^{1}$, Jihad Badra ${ }^{2 *}$, Aamir Farooq ${ }^{*}$ \\ ${ }^{1}$ Clean Combustion Research Center, King Abdullah University of Science and Technology, Thuwal, \\ Kingdom of Saudi Arabia 23955, Saudi Arabia \\ ${ }^{2}$ Fuel Technology Division, R\&D Center, Saudi Aramco, Dhahran, Saudi Arabia \\ *Corresponding authors emails: jihad.badra@aramco.com, aamir.farooq@kaust.edu.sa
}

\begin{abstract}
In this work, a universal methodology for ignition delay time (IDT) correlation of multicomponent fuel mixtures is reported. The method is applicable over wide ranges of temperatures, pressures, and equivalence ratios. n-Heptane, iso-octane, toluene, ethanol and their blends are investigated in this study because of their relevance to gasoline surrogate formulation. The proposed methodology combines benefits from the Livengood-Wu integral, the cool flame characteristics and the Arrhenius behavior of the high-temperature ignition delay time to suggest a simple and comprehensive formulation for correlating the ignition delay times of pure components and blends. The IDTs of fuel blends usually have complex dependences on temperature, pressure, equivalence ratio and composition of the blend. The Livengood-Wu integral is applied here to relate the NTC region and the cool flame phenomenon. The integral is further extended to obtain a relation between the IDTs of fuel blends and pure components. Ignition delay times calculated using the proposed methodology are in excellent agreement with those simulated using a detailed chemical kinetic model for n-heptane, iso-octane, toluene, ethanol and blends of these components. Finally, very good agreement is also observed for combustion phasing in homogeneous charge compression ignition (HCCI) predictions between simulations performed with detailed chemistry and calculations using the developed ignition delay correlation.
\end{abstract}




\section{NOMENCLATURE:}

IDT: ignition delay time

ON: octane number

CFR: cooperative fuel research engine

NTC: negative temperature coefficient

CCR: critical compression ratio

HT: high temperature

LT: low temperature

MFR: micro-flow reactor

RON: research octane number

MON: motor octane number

AKI: anti-knock index

IQT: ignition quality tester

T: temperature

P: $\quad$ pressure

$\phi: \quad$ equivalence ratio

$\tau: \quad$ overall ignition delay time

$\tau_{1}$ : first stage ignition delay time

$\tau_{\mathrm{h}}: \quad$ single stage high temperature ignition delay time

x: $\quad$ ignition carrier

$\mathbf{x}_{\mathbf{c}}$ : critical ignition carrier

L-W: Livengood-Wu integral

h-L-W: h-Livengood-Wu integral

UV: constant volume and constant energy process

$\Delta \mathbf{T}_{\mathbf{C F}}:$ temperature jump due to cool flame heat release

$\Delta \mathbf{P}_{\mathbf{C F}}$ : pressure jump due to cool flame heat release.

$\mathbf{N}$ : number of components in the fuel blend

$\mathbf{y}_{\mathbf{i}}: \quad$ mole fraction of specie $\mathrm{i}$ in the fuel blend.

$\tau_{\mathrm{i}}: \quad$ ignition delay time of component $\mathrm{i}$ of the fuel blend

$\delta_{\mathrm{i}, \mathrm{j}}: \quad$ reactivity interaction coefficient between components $\mathrm{i}$ and $\mathrm{j}$ of a fuel blend. 
$\sigma_{\mathrm{i}, \mathrm{j}}: \quad$ cool flame multiplier to account for interaction between components $\mathrm{i}$ and $\mathrm{j}$ of a fuel blend.

$\sigma: \quad$ cool flame multiplier to account for overall interactions between components of a fuel blend.

HCCI: homogeneous charge compression ignition engine

IC: internal combustion

CFD: computational fuel dynamic

PRF: primary reference fuel (n-heptane/iso-octane blend)

TPRF: toluene primary reference fuel (toluene/n-heptane/iso-octane blend)

CAD: crank angle degree 


\section{Introduction}

Ignition delay time (IDT) is an important macro information about the reactivity of fuels. It defines the time that a specific fuel mixture takes to oxidize and release heat when exposed to specific thermodynamic conditions of pressure and temperature. For engines, the gradient of IDT is a critical parameter which governs many important engine phenomena such as pre-ignition, knock and super-knock $[1,2]$. Ignition delay times of common fuels vary from micro-seconds at very high temperatures to seconds at low temperatures.

Commercial gasoline and diesel fuels are characterized according to their octane and cetane numbers which are measured in Cooperative Fuel Research (CFR) engine and Ignition Quality Tester (IQT), respectively. Octane and cetane ratings can be related to the ignition delay time of fuels which makes IDT a critical chemical property in the fuels' database [3-7]. Several studies have focused on trying to link the octane number (ON) from CFR engine to basic chemical kinetic parameters. Leppard [8] related the sensitivity of the fuel to the negative temperature coefficient (NTC) behavior of various fuels. Curran et al. [9] and Mehl et al. [10] proposed that the ON might actually correlate with the critical compression ratio (CCR). Hori et al. [11, 12] investigated possible relation between $\mathrm{ON}$ and ignition properties within micro-flow reactors (MFR). Furthermore, Singh et al. [6], Badra et al. [5], Mehl et al. [13] and Sarathy et al. [14] examined the possibilities of relating the $\mathrm{ON}$ to the homogeneous gas-phase ignition delay times. Singh et al. [6] proposed correlations between octane numbers $(\mathrm{ON})$ and ignition delay times of stoichiometric fuel/air mixtures at $750 \mathrm{~K}, 25 \mathrm{bar}$ for RON and $825 \mathrm{~K}, 25 \mathrm{bar}$ for MON. They also examined the relationship between the fuel's IDT pressure exponent and its sensitivity. Badra et al. [5] investigated the possible correlation between ON and IDT at various pressures and temperatures. They have proposed RON-like and MON-like conditions to be best representatives of the ON. Mehl et al. [13] tried to correlate the anti-knock index $(\mathrm{AKI}=(\mathrm{RON}+\mathrm{MON}) / 2)$ with ignition delay times of stoichiometric fuel/air mixtures at $825 \mathrm{~K}$ and $25 \mathrm{~atm}$, whereas Sarathy et al. [14] chose slightly different conditions ( $835 \mathrm{~K}$ and $20 \mathrm{~atm}$ ) to relate RON to homogeneous ignition delay times. Constant volume assumption was utilized in most of the simulations for the formulation of proposed correlations. Naser et al. [7] related the octane and cetane numbers of various fuel mixtures to ignition delay times measured in an ignition quality tester (IQT). 
Various experimental apparatus have been employed to measure homogenous ignition delay times. Shock tubes, rapid compression machines and ignition quality testers are the common experimental tools utilized to assess the ignition characteristics of fuels. Nowadays, detailed chemical kinetic models are available and can efficiently predict IDTs at various thermodynamic conditions. However, using these detailed (or even skeletal or reduced) mechanisms to get ignition information in engine combustion simulations can be very time consuming [15-18]. Therefore, researchers have tried to come up with correlations to calculate IDTs [3, 19-24]. These correlations ranged from a simple three-parameter Arrhenius expression [25] to codes with tens of parameters [23]. Yate et al. [26] developed a comprehensive correlation of IDT of PRF mixtures and blends of methanol with PRF 80. Their method relies on 14 parameters to correlate the IDTs of each blend [26]. Recently, Ma et al. [27] demonstrated that ignition delay times of fuel blends may be expressed as a function of individual fuel components' IDTs. They used single-component correlations, similar to Yates et al. [26], for n-heptane, iso-octane, ethanol and toluene to propose correlations for blends containing these species and tested it against wide range of experimental ignition delay times. Ma et al. [27] methodology was rather restricted to stoichiometric mixtures and presented some limitations in predicting IDTs of blends at intermediate and low temperatures where chemical interactions are expected to alter the autoignition characteristics of fuel blends [27]. In the present work, we aim to upgrade Yates et al. [26] and Ma et al. [27] methodologies and provide a straightforward correlation method to rapidly get the IDTs of a fuel mixture over a wide range of conditions.

It is widely accepted that the ignition delay time is strongly dependent on temperature and this relationship can be described by an Arrhenius slope similar to that of reaction rate coefficients [28]. Mullins [29] (in 1951) and Miller [30] (in 1958) provided illustrative Arrhenius plots of IDT that covered a wide range of fuels and conditions. In addition, it is widely accepted that IDT depends on pressure and fuel concentration according to this modified Arrhenius expression [20, 25, 31]:

$$
\tau=A \cdot \prod\left[X_{i}\right]^{a i} \cdot P^{n} \cdot \exp \left(\frac{E}{R T}\right)
$$

where $\tau$ is the ignition delay time at temperature $\mathrm{T}$ and pressure $\mathrm{P},\left[X_{i}\right]$ represents the concentration of various mixture species (oxygen, fuel, nitrogen, etc.), $\mathrm{A}$ is the pre-exponential parameter, $a_{\mathrm{i}}$ is 
the power dependence coefficient of species concentration, $n$ is the power dependence coefficient of pressure, $\mathrm{E}$ is the activation energy and $\mathrm{R}$ is the gas constant. Equation (1) was proven to be a good correlation for IDTs, particularly for high temperatures (usually $>1000 \mathrm{~K}$ ) and for simple fuels [32]. At intermediate temperatures $(650 \mathrm{~K}<\mathrm{T}<900 \mathrm{~K})$, some fuels, such as n-heptane and iso-octane, show a negative temperature dependence (NTC) region which is manifested by a curvature and decrease of ignition delay times with decreasing temperature in the Arrhenius plot $\ln (\tau)=\mathrm{f}(1 / \mathrm{T})[33,34]$. In this case, a simple expression like Eq. (1) is no longer a good representation of the ignition delay times. Many physiochemical explanations of the NTC behavior are provided in literature and these are mainly summarized into two phenomena: (a) cool flame effect and (b) coupling of low-temperature and high-temperature chemistry. Weisser [35] was the first to relate high- and low- temperature kinetics observation of the NTC and was able to correlate it using a parallel resistant-like model where the high-, intermediate- and low-temperature ignition delay times are coupled to draw the final S-shape of total ignition delay time. This was further adopted by Blomberg et al. [36], Steurs et al. [37] and Vandersickel [38]. On the other hand, many other researchers reported that the cool flame initiation is the cause for accelerating ignition phenomena in the NTC region [26, 39].

In the current paper, a relatively simple phenomenological description of IDT is presented that not only depends on empirical findings but rather on physical descriptions of the ignition phenomena. Specifically, the Livengood-Wu description [20] is adopted to calculate the ignition delay times of pure components (n-heptane, iso-octane, toluene and ethanol). Subsequently, a descriptive algorithm is formulated and applied to predict the ignition delay times of fuel blends. Finally, the proposed algorithm is validated against HCCI engine simulations using detailed chemistry. 


\section{Livengood-Wu Integral}

\subsection{Proof of Livengood-Wu Integral}

The Livengood-Wu (L-W) integral describes the advancement of a specific mixture towards ignition. Its formulation is [20]:

$$
\frac{x(t)}{x\left(\tau_{\text {ign }}\right)}=\int_{t=0}^{t} F\left(\frac{t}{\tau}\right) \cdot d t
$$

where $x$ describes the amplitude (or concentration) of an ignition carrier, $\tau$ is the ignition delay time at the conditions corresponding to time $\mathrm{t}$ (pressure, temperature and composition at time $\mathrm{t}$ ), $\tau_{i g n}$ is the overall ignition delay time of the mixture and $F$ is an empirical function. The identity of the ignition carrier is not well understood [40-42]. The best approximation so far for $x$ could be the heat release or the concentration of carbon monoxide [40].

As stated by Livengood and $\mathrm{Wu}$ [20], the physical interpretation of the $\mathrm{L}-\mathrm{W}$ integral is that the amplitude of ignition carriers $\mathrm{x}$ can only increase towards its critical value, $\mathrm{x}_{\mathrm{c}}$, at ignition and this can be described as:

$$
\frac{x}{x_{c}}=f\left(\frac{t}{\tau}\right)
$$

where $f$ is an increasing function such that $f(0)=0$ and $f(1)=1$. Thus, $f$ is reversible and if we denote $h=f^{-1}$, then Eq. (3) becomes:

$$
\frac{t}{\tau}=h\left(\frac{x}{x_{c}}\right)
$$

where $\mathrm{h}$ is also an increasing function such that $h(0)=0$ and $h(1)=1$. The ignition delay time $\tau$ is not directly dependent on time but rather depends on pressure and temperature which can be functions of time.

If we assume that in the interval $[t, t+d t]$, pressure and temperature are constant, thus $\tau$ is also constant in this interval and Eq. (4) becomes:

$$
\frac{d\left(h\left(\frac{x}{x_{c}}\right)\right)}{d t}=\frac{1}{\tau}
$$


A more rigorous derivation of the previous expression is available in the Appendix. If we integrate Eq. (5) we find:

$$
h\left(\frac{x(t)}{x_{c}\left(\tau_{i g n}\right)}\right)=\int_{0}^{t} \frac{1}{\tau} d t
$$

Equation (6) is another way of writing the L-W integral expressed in Eq. (2). Equation (6) is simpler than Eq. (2) since the unknown function is no longer inside the integral. For convenience, it will be called here the h-Livengood-Wu (h-L-W) integral. Many of the properties classically derived using the Livengood-Wu integral under augmented assumptions can now be derived in a much simpler and rigorous manner. For instance, at time $t=\tau_{i g n}$, we have $x=x_{c}$ and thus $h(x / x c)=h(1)=1$ and we have:

$$
1=\int_{0}^{\tau_{i g n}} \frac{1}{\tau} d t
$$

Livengood and $\mathrm{Wu}$ [20] were able to derive Eq. (7) only by assuming a zeroth order kinetics for which the F function in Eq. (2) becomes constant. In fact, the h-L-W integral shows that Eq. (4) is valid even in the case of no clear order of kinetics. This may explain the success of the L-W integral despite the general non-zeroth order of kinetics of most reactions during combustion. Similar findings and further restrictive analyses are given in the Appendix and also by Pan et al. [19] where it is demonstrated that the L-W integral is valid for any global kinetics order. A detailed section about the applicability of the Livengood-Wu integral is also provided in the Appendix.

\subsection{Livengood-Wu integral and NTC behavior}

Previous works [19, 35-38] have divided the IDT plot of fuels that show NTC region into three domains: (a) the high-temperature (HT) region (usually higher than $1000 \mathrm{~K}$ ) in which the IDT is a simple Arrhenius function of temperature, pressure and composition (see Eq. (1)), (b) the lowtemperature (LT) region (usually lower than $650 \mathrm{~K}$ ) in which the IDT is also a simple Arrhenius function (see Eq. (1)), (c) intermediate-temperature or NTC region where the cool flame phenomena becomes important (see Fig. 1). 


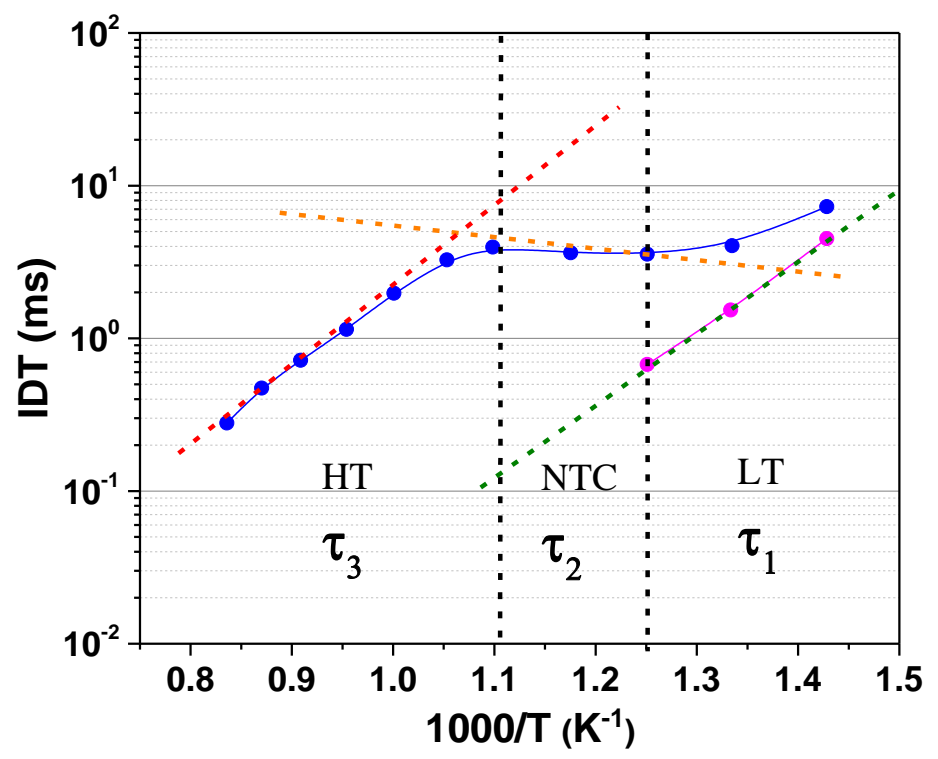

Figure 1: Three distinct regions of fuel reactivity (figure adapted from Blomberg[36]). Blue dots are overall ignition delay times. Magenta dots are $1^{\text {st }}$ stage ignition delay times.

Yates et al. [26] suggested that the increased reactivity in the NTC region is solely caused by the cool flame temperature and pressure rises. In fact, after dividing the IDT behavior into two regions (before and after the cool flame development), the Livengood-Wu integral becomes:

$$
1=\int_{0}^{\tau} \frac{1}{\tau_{h}(T, P)} d t=\int_{0}^{\tau_{1}} \frac{1}{\tau_{h}\left(T_{0}, P_{0}\right)} d t+\int_{\tau_{1}}^{\tau} \frac{1}{\tau_{h}\left(T_{0}+\Delta T_{C F}, P_{0}+\Delta P_{C F}\right)} d t
$$

where $\tau_{1}$ is the pre-cool flame ignition delay time (or $1^{\text {st }}$ stage IDT), $\tau_{h}$ is the high temperature Arrhenius ignition delay time, $\Delta T_{C F}$ and $\Delta P_{C F}$ are the temperature and pressure increases following the cool flame heat release. Neglecting $T$ and $P$ variations from $\mathrm{t}=0$ to the initiation of pre-cool flame time and from the end of the cool flame to the second stage ignition delay time, the overall ignition delay time can then be expressed as:

$$
\tau(T, P)=\tau_{1}+\tau_{h}\left(T+\Delta T_{C F}, P+\Delta P_{C F}\right) \cdot\left(1-\frac{\tau_{1}(T, P)}{\tau_{h}(T, P)}\right)
$$

\section{Ignition Delay Times of a Multi-component Fuel Blend}

\subsection{Formulation}

In this section, we suggest a formulation to correlate the ignition delay times of a fuel mixture of $N$ pure components, $X i(i=1 \ldots N)$, where each component has a molar fraction of $y_{i}$. To obtain a 
first approximation of the ignition delay time of a mixture of components, independent chemistry is assumed. Hence, the effect of the cross-over reactions is neglected and it is suggested that the individual components, $X i$, of the mixture react independently and advance simultaneously towards ignition. In this sense, the oxygen content of the mixture is divided among the different components and the individual equivalence ratio $\phi_{i}$ of each $X i$ can be defined as following:

$$
\phi_{i}=\phi
$$

The h-L-W integral applied for the mixture is:

$$
\frac{d\left(h\left(\frac{x}{x_{c}}\right)\right)}{d t}=\frac{1}{\tau}
$$

where $x$ is the ignition carrier amplitude due to the reactions from all fuel components $X i$. With the assumption of independent chemistry interactions, it can be written as:

$$
x=\sum_{i=1}^{N} x_{i}
$$

where $x_{i}$ is the carrier concentration caused by the component $X i$ as it advances towards ignition. The simultaneous advancement towards ignition of all fuel components translates to:

$$
x_{i, c}=y_{i} \cdot x_{c}
$$

where $x_{i, c}$ is the ignition carrier concentration produced by the ignition of component $i$ of the blend, $x_{c}$ is the concentration of the ignition carrier at the critical conditions (i.e., at ignition) produced by the ignition of all components of the blend. The critical concentration $x_{c}$ of the carrier is supposed to be a universal constant that does not depend on the initial mixture composition or thermodynamic conditions [20]. Thus, we obtain Eq. (14):

$$
\left(\frac{x}{x_{c}}\right)=\left(\sum_{i=1}^{N} y_{i} \frac{x_{i}}{x i, c}\right)
$$

Invoking Eq. (4), Eq. (14) can also be rewritten in the form of Eq. (15):

$$
\left(\frac{x}{x_{c}}\right)=\sum_{i=1}^{N} y_{i} h^{-1}\left(\frac{t}{\tau_{i}}\right)
$$


At the ignition delay time of the mixture, we have:

$$
h\left(\frac{x_{i}}{x_{c}}\right)=\int_{0}^{\tau_{i g n}} \frac{1}{\tau_{i}} \cdot d t=\frac{\tau_{i g n}}{\tau_{i}} \text { and } h\left(\frac{x}{x_{c}}\right)=1
$$

Thus, we obtain Eq. (16):

$$
1=\sum_{i=1}^{i=N} y_{i} h^{-1}\left(\frac{\tau_{i g n}}{\tau_{i}}\right)
$$

Equation (16) allows the calculation of ignition delay times of a fuel blend based on the individual components' ignition delay times. It is important to note here that in the particular case of the zeroth order kinetics, $h$ simplifies to the identity function. In this case, for a single stage ignition phenomena, we obtain:

$$
\frac{1}{\tau(T, P, \phi)}=\sum_{i=1}^{N} y_{i} \frac{1}{\tau_{i}(T, P, \phi)}
$$

Equation (17) was also suggested by other authors [27] following different analysis. If we suppose a non-zero order of kinetics $n$, then the function $h$ is defined as:

$$
h\left(\frac{x}{x_{c}}\right)=\left(\frac{x}{x_{c}}\right)^{1-n}
$$

In this case, Eq. (17) becomes:

$$
\frac{1}{(\tau(T, P, \phi))^{\frac{1}{1-n}}}=\sum_{i=1}^{N} y_{i} \frac{1}{\left(\tau_{i}(T, P, \phi)\right)^{\frac{1}{1-n}}}
$$

To allow for some kinetic dependence and to account for the effect of cross-over reactions, the ignition carrier can be assumed to be produced by two phenomena: (a) advancement of each fuel towards ignition, and (b) chemical interaction of fuel components. The second factor is obviously a function of the concentration of the two fuel components and their chemical interactions. At first order, this can be modeled as:

$$
x_{i}=x_{i, i}+x_{i, i} \sum_{\substack{j=1 \\ j \neq i}}^{j=N} y_{j} \delta_{i, j}
$$

where $\delta_{i, j}$ represents the effect of cross-over reactions of specie $i$ and specie $j$ in the mixture. $\delta_{i, j}$ is zero in the case of negligible chemical interactions. 
The total production of the ignition carrier can be then written as:

$$
\frac{x}{x_{c}}=\sum_{i=1}^{N} \frac{y_{i} x_{i}}{x_{i, c}}=\sum_{i=1}^{N} \frac{x_{i, i}}{x_{i, c}} y_{i}\left(1+\sum_{\substack{j=1 \\ j \neq i}}^{j=N} y_{j} \cdot \delta_{i, j}\right)
$$

Thus, we obtain Eq. (22):

$$
\left(\frac{x}{x_{c}}\right)=\sum_{i=1}^{i=N} y_{i}\left(1+\sum_{\substack{j=1 \\ j \neq i}}^{j=N} y_{j} \cdot \delta_{i, j}\right) h^{-1}\left(h\left(\frac{x_{i, i}}{x_{i, c}}\right)\right)
$$

Then at ignition, we obtain Eq. (23):

$$
1=\sum_{i=1}^{i=N} y_{i}\left(1+\sum_{\substack{j=1 \\ j \neq i}}^{j=N} y_{j} \cdot \delta_{i, j}\right) h^{-1}\left(\frac{\tau_{i g n}}{\tau_{i}}\right)
$$

If we assume $\mathrm{n}^{\text {th }}$ order of kinetics for the carrier $x$, then we get:

$$
\frac{1}{(\tau(T, P, \phi))^{\frac{1}{1-n}}}=\sum_{i=1}^{N} y_{i}\left(1+\sum_{\substack{j=1 \\ j \neq i}}^{j=N} y_{j} \cdot \delta_{i, j}\right) \frac{1}{\left(\tau_{i}(T, P, \phi)\right)^{\frac{1}{1-n}}}
$$

Equation (24) is a relation between the ignition delay of the individual components of a blend and the overall ignition delay time of the blend. It is more general than Eq. (19) because it takes into account chemical interactions between the mixture components and the non-zeroth order of kinetics. The interaction coefficient $\delta_{i, j}$ may be dependent on temperature, pressure, equivalence ratio and overall composition. In order to account for the chemical interaction effect, more than 5000 ignition delay simulations of pure, binary, ternary and quaternary mixtures of n-heptane, isooctane, toluene and ethanol were performed using the 'FACE gasoline surrogate mechanism' of Sarathy et al. [43]. The conclusion drawn from these simulations is that the chemical interactions 
can be expressed as effective cool flame $\mathrm{T}$ and $\mathrm{P}$ increases, as will be detailed in the following sections.

\subsection{Algorithm}

In this section, the details given in the previous sections are summarized. The correlation of the IDT of a multicomponent mixture ( $N$ components) applicable over wide ranges of temperatures, pressures, equivalence ratios and compositions can be established by following the below steps:

i. $\quad$ Provide the correlation parameters of IDTs for all $N$ pure components of the mixture. If the Yates et al. [26] correlation is adopted, a total of 15 parameters should be given for each of the pure components.

ii. Provide the $N(N-1) / 2$ second order chemical interaction coefficients $\delta i, j$ for each combination of the two components $i$ and $j$. These coefficients can be obtained by best fit of binary mixture IDTs as a function of the individual IDTs of each of its components $i$ and $j$ using Eq. (24), in which case the only unknown would be $\delta i, j$. These coefficients $\delta i, j$ are in fact implicit and it is hard to give an explicit expression for these as a function of mixture conditions. The best way to account for these coefficients is by using effective cool flame temperature and pressure rise multiplier, $\sigma_{\mathrm{i}, j}$, as will be shown later.

iii. Use Eq. (24) to get the staged ignition delay times $\tau_{1}$ and $\tau_{\mathrm{h}}$ of the mixture.

iv. Use Eq. (9) to calculate the overall ignition delay time of the mixture.

Steps (i) and (ii) are about the generation of parameters needed for the ignition delay time correlation. These parameters can be determined either by fitting the simulated or measured ignition delay times. In the following section, values of these parameters for n-heptane, iso-octane, toluene and ethanol are evaluated based on the simulated ignition delay times over a range of pressures (10, 30 and $50 \mathrm{~atm})$, temperatures $(600-1300 \mathrm{~K})$, and equivalence ratios $(0.5$, 1, and $1.5)$. 


\subsection{Ignition Delay Time Correlation}

\subsubsection{Ignition delay times of single-component fuels}

The aim of this section is to provide an illustrative example of the step (i) of the algorithm presented in the previous section. The correlation formulation for pure components given by Yates et al. [26] is adopted here. The FACE gasoline surrogate mechanism [43] is utilized to obtain wideranging ignition delay time data to determine the correlation parameters. Yates et al. [26] reported that 15 parameters are needed to adequately correlate the ignition delay times of fuels over wide ranges of temperatures, pressures and equivalence ratios. They used Westbrook and Curran mechanisms of iso-octane and $n$-heptane $[33,34]$ to derive values of these parameters for $n$ heptane and iso-octane. The derived parameters are obviously mechanism-dependent because these are found by fitting the simulated IDTs to the correlation functions. In our work, values of these parameters are found by fitting to the simulations carried out using the FACE gasoline surrogate mechanism for $n$-heptane, iso-octane, ethanol and toluene mixtures in air $\left(3.76 / 1: \mathrm{N}_{2} / \mathrm{O}_{2}\right)$. The obtained parameters are listed in Table 1 and these are slightly different than those obtained by Yates et al. [26] for $\mathrm{n}$-heptane and iso-octane. The differences in the parameters are obviously caused by the different mechanisms used here and by Yates et al. [26]. The cool flame T rises are obtained by measuring the simulated temperature jump between the inflection points before and after the first stage ignition. In Fig. 2, the correlated ignition delay times are plotted versus the simulated ignition delay times for the four studied fuels. Overall, the correlation is able to reproduce the simulated results within $3 \%$ average deviation. 
Table 1: Correlation parameters of the IDTs of n-heptane, iso-octane, toluene and ethanol in air (3.76/1: $\left.\mathrm{N}_{2} / \mathrm{O}_{2}\right)$ based on Yates et al. methodology and fitted to the FACE gasoline surrogate mechanism [43] simulations.

\section{Fuels Correlation parameters}

High-temperature IDT:

\begin{tabular}{ccccc} 
& \multicolumn{2}{c}{$\tau_{h}=A_{h} \cdot \phi^{\beta_{h}} \cdot P^{n_{h}} \cdot \exp \left(\frac{B_{h}}{T}\right)$} & & \\
\cline { 2 - 5 } & $A_{h}$ & $n_{h}$ & $B_{h}$ & $\beta_{h}$ \\
\hline n-Heptane & $3.33 \mathrm{E}-02$ & -1.2 & 14401 & -0.55 \\
\hline iso-Octane & $0.36 \mathrm{E}-02$ & -1 & 16369 & -0.5 \\
\hline Ethanol & $0.82 \mathrm{E}-03$ & -0.87 & 16766 & -0.61 \\
\hline Toluene & $2.96 \mathrm{E}-03$ & -1.04 & 18216 & -0.32 \\
\hline
\end{tabular}

\begin{tabular}{|c|c|c|c|c|c|}
\hline & \multicolumn{2}{|c|}{$\tau_{1}=A_{1} \cdot P^{n_{1}} \cdot T^{m 1} \cdot \phi^{\beta_{1}} \cdot \exp \left(\frac{B_{1}}{T}\right)$} & \multirow[b]{2}{*}{$B_{1}$} & \multirow[b]{2}{*}{$\beta_{1}$} & \multirow[b]{2}{*}{$m_{1}$} \\
\hline & $A_{1}$ & $n_{1}$ & & & \\
\hline n-Heptane & $6.46 \mathrm{E}-06$ & -0.03 & 14210 & -0.07 & 0 \\
\hline iso-Octane & $1.78 \mathrm{E}-19$ & -0.255 & 51 & -0.22 & 57.7 \\
\hline Ethanol & NA & NA & NA & NA & NA \\
\hline Toluene & NA & NA & NA & NA & NA \\
\hline
\end{tabular}

Cool flame parameters:

$$
\begin{gathered}
T_{C F}=T i+0.5\left(\Delta T_{C F}+\sqrt{\left(\Delta T_{C F}\right)^{2}+C_{0}}\right) \\
\Delta T_{C F}=\omega\left(T_{i}-T_{E Q} \cdot p^{\kappa} \cdot \phi^{m u} \cdot\left(\frac{100}{99+\phi}\right)^{\text {sigma }}\right)
\end{gathered}
$$

\begin{tabular}{ccccccc} 
& $\mathrm{T}_{\mathrm{EQ}}$ & $\omega$ & $\kappa$ & $\mathrm{C}_{0}$ & $\mathrm{mu}$ & sigma \\
\hline n-Heptane & 865 & -1.407 & 0.031 & 1145 & $32 \mathrm{E}-3$ & 1.41 \\
\hline iso-Octane & 680 & -1.731 & 0.061 & 4734 & $-18 \mathrm{E}-4$ & -5.08 \\
\hline Ethanol & NA & NA & NA & NA & NA & NA \\
\hline Toluene & NA & NA & NA & NA & NA & NA \\
\hline
\end{tabular}

*NA: Not applicable; toluene and ethanol do not exhibit two-stage ignition 


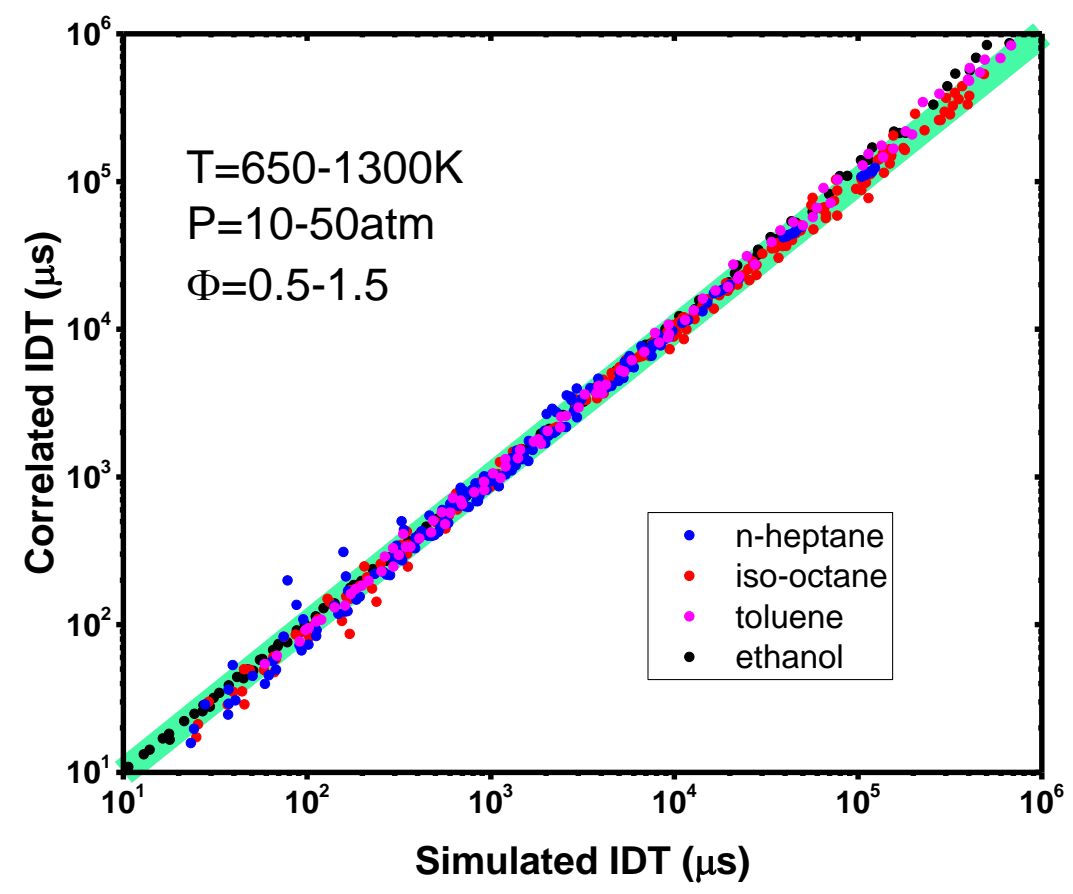

Figure 2: Performance of IDT correlation for single-component fuels (green background line width represents $\pm 20 \%$ deviations)

\subsubsection{Ignition delay times of binary mixtures}

The aim of this section is to provide illustrative example of step (ii) of the algorithm presented in section 3.2. It is worth noting here that the second order coefficients $\delta_{i, j}$ are expected to be characteristic of components $i$ and $j$. Therefore, ignition delay simulations of different binary mixtures of n-heptane, iso-octane, ethanol and toluene were performed using the FACE gasoline surrogate mechanism [43]. These simulations were carried out for different conditions of temperature $(650-1300 \mathrm{~K})$, pressure $(10,30$ and $50 \mathrm{~atm})$, equivalence ratio $(0.5,1$ and 1.5$)$ and mixture mole fractions (0.1/0.9 0.2/0.8 and 0.5/0.5). Subsequently, Eq. (9) and Eq. (22) were used to calculate the ignition delay time of the binary mixtures. It is noted here that while using Eq. (9), the cool flame properties of the mixture are needed. Ma et al. [27] reported that the cool flame temperature rise of the mixture can be calculated by the specific-heat-weighted cool flame temperature rises of individual components according to the following averaging formula:

$$
\Delta T_{C F}=\frac{\sum_{i=1}^{N} \mathrm{y}_{\mathrm{i}} \mathrm{C}_{\mathrm{p}, \mathrm{i}} \Delta T_{C F, i}}{\sum_{i=1}^{N} \mathrm{y}_{\mathrm{i}} \mathrm{C}_{\mathrm{p}, \mathrm{i}}}
$$


where $\mathrm{C}_{\mathrm{p}, \mathrm{i}}$ is the molar heat capacity at constant pressure of component $i, y_{i}$ is the mole fraction of component $i$ and $\Delta T_{C F, i}$ is the cool flame temperature rise of pure component $i$ at the thermodynamic conditions of the fuel blend. The cool flame heat release is conventionally defined to be occurring in a constant volume reactor rather than a constant pressure process. Therefore, in our formulation, the molar heat capacity at constant volume $\mathrm{C}_{\mathrm{v}, \mathrm{i}}$ is used instead of $\mathrm{C}_{\mathrm{p}, \mathrm{i}}$. Secondly, the energy released during cool flame is used to heat all mixture components including oxygen and nitrogen. Thus, a modified averaging formula for the cool flame temperature rise is introduced and represented by Eq. (26):

$$
\Delta T_{C F}=\frac{\left(\sum_{i=1}^{N} y_{i} \cdot\left(\phi \cdot C_{v, C w_{i} H x_{i} O z_{i}}+\left(\frac{x_{i}}{4}+w_{i}-\frac{z_{i}}{2}\right) \cdot\left(C_{v, O_{2}}+3.76 \cdot C_{v, N_{2}}\right) \Delta T_{C F, i}\right)\right.}{\sum_{i=1}^{N} y_{i}\left(\phi \cdot C_{v, C w_{i} H x_{i} O z_{i}}+\left(\frac{x_{i}}{4}+w_{i}-\frac{z_{i}}{2}\right) \cdot\left(C_{v, O_{2}}+3.76 \cdot C_{v, N_{2}}\right)\right)}
$$

where $\mathrm{Cw}_{i} \mathrm{Hx}_{i} \mathrm{Oz} z_{i}$ is the chemical formula of component $X_{i}$ of the fuel blend. It is also worth noting that the pressure and temperature increases during cool flame are mainly due to the heat release and not due to the increase in species concentrations. Thus, the pressure rise can be related to the temperature rise through the ideal gas equation:

$$
\frac{\Delta P_{C F}}{P}=\frac{\Delta T_{C F}}{T}
$$

Furthermore, $\delta_{\mathrm{i}, \mathrm{j}}$ and $n$ in Eq. (24) are varied for each binary mixture combination to best fit the simulated mixture IDTs using pure components IDTs. During the fitting procedure, it was found that the zeroth order of kinetics $(n=0)$ produced the best fitting results. Secondly, it was hard to find a simple explicit expression of the interaction coefficients $\delta_{i, j}$ as a function of the mixture conditions (temperature, pressure, composition). It was noticed that Eq. (19) was sufficient to give good predictions of $1^{\text {st }}$ stage IDTs and also for single stage IDTs but not for the post cool flame ignition timing. Thus, chemical interactions seem to have noticeable effects only at the post cool flame conditions. Therefore, it was chosen to transform the chemical interaction effects into effective cool flame temperature and pressure rises, similar to the methodology adopted by Yates et al. [26] for pure components (refer to the $x$ parameters in Yates et al. formulation [26]). For each binary mixture, the cool flame $\mathrm{T}$ and $\mathrm{P}$ rises are first calculated using Eq. (26) and then multiplied by a coefficient $\sigma_{i, j}$, which represents the effect of chemical interactions between the two fuel components in the mixture, to calculate the post cool flame ignition delay time: 


$$
\tau_{h, C F}=A_{h \cdot} \phi^{\beta_{h}} \cdot\left(P+\sigma_{i, j} \cdot \Delta P_{C F}\right)^{n_{h}} \cdot \exp \left(\frac{B_{h}}{T+\sigma_{i, j} \cdot \Delta T_{C F}}\right)
$$

Correlation results are shown in Fig. 3 and compared with the case where no chemical interactions are considered $\left(\delta_{i, j}=0\right)$. The optimized chemical interaction coefficients are summarized in Table 2.
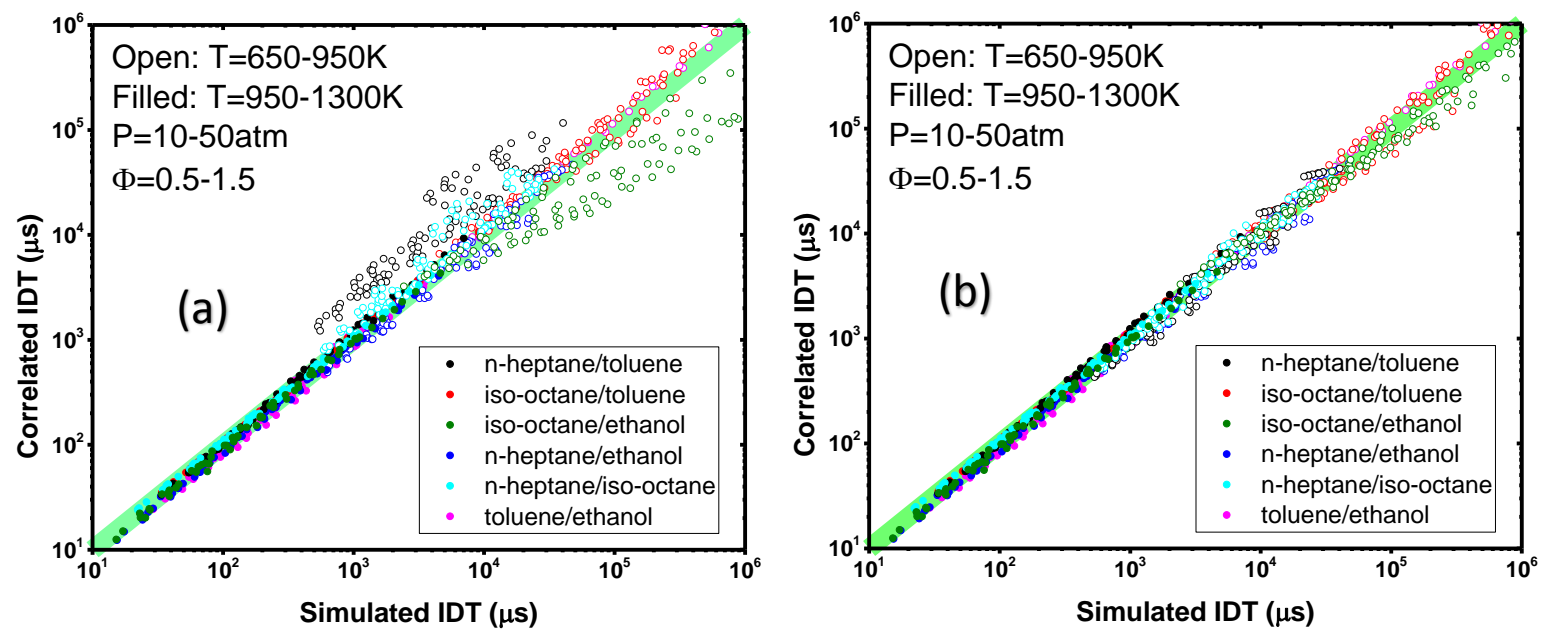

Figure 3: Performance of ignition delay time correlation for binary mixtures (only $0.5 / 0.5$ binary mixtures are shown). (a) Without chemical interactions $\left(\sigma_{i, j}=1\right.$ or $\left.\delta_{i, j}=0\right)$. (b) With chemical interactions. Simulations are performed using the FACE gasoline surrogate mechanism [43]. Distinction is made between the low $\mathrm{T}(650-950 \mathrm{~K})$ cases and high $\mathrm{T}$ cases $(950-1300 \mathrm{~K})$ by open and filled symbols to highlight the low $\mathrm{T}$ window where chemical interactions are important to consider.

By comparing Fig. 3(a) and Fig. 3(b), it is observed that the inclusion of chemical interaction has improved the IDT correlation significantly; the average deviation between the correlation and the simulation decreased from $\sim 34 \%$ to $11 \%$. Table 2 suggests that the chemical interaction coefficients either vary between $1-1.3$ or depend on the molar fraction of the fuel components in the mixture. An interaction coefficient $\sigma_{i, j}$ of 1 means that the chemical interactions are not important and that a simple blending formula, as in Eq. (19), is sufficient to get ignition delay correlation of a blend. An interaction coefficient higher than 1 means that chemical interactions increase the reactivity of the blend than what would be expected from a simple linear blending rule. Likewise, an interaction coefficient smaller than 1 (e.g., $y_{\text {iso-octane) means that chemical }}$ interactions inhibit the reactivity of the blend. For example, ethanol seems to inhibit the ignition of iso-octane but it does not alter the reactivity of n-heptane. Detailed sensitivity and rate-ofproduction analyses may be performed to gain fundamental understanding of these interaction 
coefficients. However, such analyses and discussions are beyond the scope of the current work. The coefficients given in Table 2 were calculated by fitting the simulated ignition delay times obtained from the FACE gasoline surrogate mechanism [43].

Table 2: Chemical interaction coefficients, $\sigma_{\mathrm{i}, \mathrm{j}}$, for the various components considered in this work. $y_{i}$ represents the molar fraction of fuel component $i$.

\begin{tabular}{c|c|c|c|c}
\hline & iso-Octane & n-Heptane & Toluene & Ethanol \\
\hline iso-Octane & 1 & 1.3 & 1.2 & $y_{\text {iso-octane }}$ \\
\hline n-Heptane & 1.3 & 1 & $\frac{1}{y_{n-\text { heptane }}}$ & 1 \\
\hline Toluene & 1.2 & $\frac{1}{y_{n-\text { heptane }}}$ & 1 & 1 \\
\hline Ethanol & $y_{\text {iso-octane }}$ & 1 & 1 & 1 \\
\hline
\end{tabular}

\subsubsection{Ignition delay times of multi-components mixtures}

The aim of this part is to provide illustrative example of the steps (iii) and (iv) of the correlation algorithm. Provided with correlation parameters for the individual IDTs ( $\tau_{\mathrm{h}}$ and $\tau_{\mathrm{CF}}$ ) for the various components of the mixture and the coefficients $\sigma_{\mathrm{i}, \mathrm{j}}$ that represent the interaction between these components, the mixture IDTs can be obtained by combining Eq. (9) and Eq. (24). The interaction parameter $\sigma$ for the mixture can be approximated by the average of the mutual interaction coefficients $\sigma_{\mathrm{i}, \mathrm{j}}$ between the mixture components, according to Eq. (29):

$$
\sigma=\frac{1}{N-1} * \sum_{\substack{i, j=1 \\ i \neq j}}^{N} y_{j} \sigma_{i, j}
$$



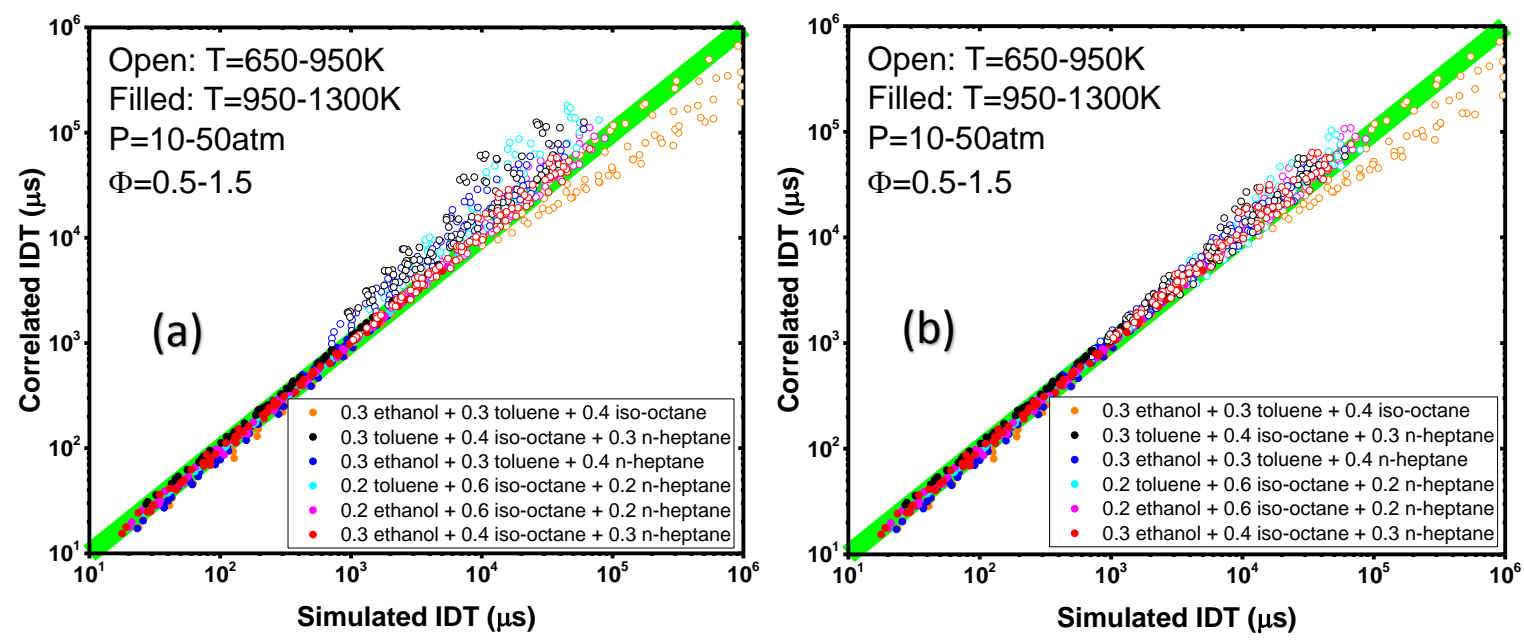

Figure 4: Performance of IDT correlation for ternary mixtures. (a) Without chemical interactions. (b) With chemical interactions. The fractions given in the legend represent molar fractions of fuel components. Simulations are performed using the FACE gasoline surrogate mechanism [43].
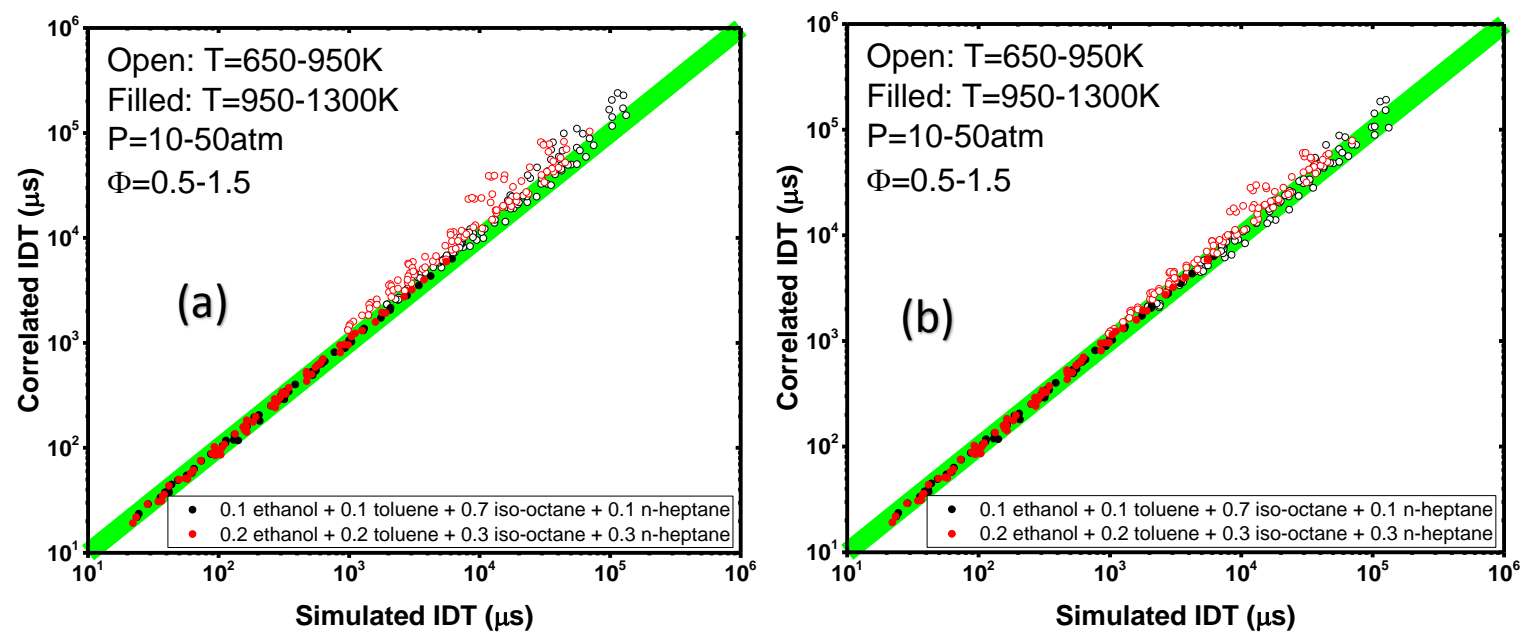

Figure 5: Performance of ignition delay time correlation for quaternary mixtures. (a) Without chemical interactions. (b) With chemical interactions. The fractions given in the legend represent molar fractions of fuel components. Simulations are performed using the FACE gasoline surrogate mechanism [43].

Figures 4 and 5 compare the correlated IDTs of ternary and quaternary mixtures of iso-octane, $\mathrm{n}$ heptane, ethanol and toluene in air $\left(3.76 / 1: \mathrm{N}_{2} / \mathrm{O}_{2}\right)$ with the simulated ones over a wide range of pressures, temperatures, equivalence ratios and compositions. Similar to the case of binary mixtures, the correlation methodology proposed in the current work performs well in predicting the simulated IDTs. A Matlab code based on the algorithm presented here is provided in the Supplementary Material. This code may be used as a simple and computationally efficient method to calculate autoignition and time of peak heat release rate of various mixtures over a range of 
thermodynamic conditions. We believe that such a code will be very helpful for engine simulations of gasoline surrogates.

\section{Application to HCCI Combustion}

Reactive internal combustion (IC) engine simulations require the simultaneous solution of various physical and chemical equations. Robust chemistry is usually solved using detailed chemical kinetic mechanisms that may contain thousands of species and chemical reactions making these kinds of simulations complex and very time consuming. Researchers make use of reduced or skeletal mechanisms that are simplified and tailored to a specific kind of application (specific reactive systems, fuel mixture, temperature, pressure and equivalence ratio ranges). The skeletal or reduced mechanisms, however, suffer from the drawback of being non-universal and, nevertheless, do contain some degree of complexity that may pose limitations for expensive CFD reactive simulations. Many CFD targeted engine simulations focus on studying physiochemical phenomena such as pre-ignition, knock (normal and super), heat release, cycle-to-cycle variations, heat transfer and more. Such kind of simulations only require information about the local low-T heat release and ignition timings. Therefore, ignition delay time correlations could be particularly useful to predict the ignition event without the need to solve complex and time consuming chemical reactions.

As an illustration, the correlation presented in the previous sections is utilized to predict the lowtemperature and main heat release timing for a homogenous charged compression ignition (HCCI) engine operation where the auto-ignition of the premixed fuel/air mixture is the primary controlling event. The predictions are compared with detailed simulations using the FACE gasoline surrogate mechanism [43] and the HCCI reactor model in Chemkin [44]. The HCCI engine properties used for these simulations are given in Table 3. Three fuels in air $\left(3.76 / 1: \mathrm{N}_{2} / \mathrm{O}_{2}\right)$ with the same RON (91) and different compositions are tested here at an equivalence ratio of 0.7 . The three fuels are PRF 91, TPRF 91 and TPRF+ethanol 91. The TPRF 91 surrogate was formulated using the methodology of Kalghatgi et al. [2] and the TPRF+ethanol 91 surrogate was developed using the method of AlRamadan et al. [45]. The composition, RON and MON of the studied surrogates are provided in Table 4. 
Table 3: HCCI engine parameters for the simulations

\begin{tabular}{llllllll}
$\begin{array}{l}\text { Engine } \\
\text { speed } \\
(\mathbf{r} / \mathbf{m i n})\end{array}$ & $\begin{array}{l}\text { Compressio } \\
\mathbf{n} \text { ratio }\end{array}$ & $\begin{array}{l}\text { Bore } \\
(\mathbf{c m})\end{array}$ & $\begin{array}{l}\text { Stroke } \\
(\mathbf{c m})\end{array}$ & $\begin{array}{l}\text { Connection } \\
\mathbf{r o d}(\mathbf{c m})\end{array}$ & $\begin{array}{l}\text { Piston } \\
\text { offset }\end{array}$ & $\begin{array}{l}\text { Temperature } \\
(\mathbf{K})\end{array}$ & $\begin{array}{l}\text { Pressure } \\
(\mathbf{a t m})\end{array}$ \\
\hline $\mathbf{6 0 0}$ & 16 & 8.6 & 9.46 & 14.8 & 0 & $293-353$ & 2 \\
\hline
\end{tabular}

Table 4: Composition of the three surrogates used for HCCI engine simulations

\begin{tabular}{|c|c|c|c|c|c|c|}
\hline Blend & RON & MON & $\begin{array}{l}\text { n- } \\
\text { Heptane } \\
(\%)\end{array}$ & $\begin{array}{l}\text { iso- } \\
\text { Octane } \\
(\%)\end{array}$ & $\begin{array}{l}\text { Toluene } \\
(\%)\end{array}$ & $\begin{array}{l}\text { Ethanol } \\
(\%)\end{array}$ \\
\hline PRF91 & 91 & 91 & 9 & 91 & 0 & 0 \\
\hline TPRF91 & 91 & 83.4 & 17.1 & 28.9 & 54 & 0 \\
\hline TPRF+ethanol 91 & 91.1 & 83.5 & 16.6 & 22.5 & 40.9 & 20 \\
\hline
\end{tabular}

A Matlab script was coded which enables prediction of the crank angle degrees (CAD) for the low$\mathrm{T}$ heat release and for the main ignition event using the correlation presented in this work. The Matlab script is provided in the Supplementary Material. Figure 6 summarizes the results obtained for the three surrogates at an equivalence ratio of 0.7 , and comparison is made between full Chemkin HCCI simulations and the correlation based predictions. The correlation is able to predict the CAD for both the low-temperature heat release and the main heat release with an average deviation of $1 \mathrm{CAD}$ for intake temperatures ranging from 20 to $80{ }^{\circ} \mathrm{C}$. The reasons for some deviations seen in Fig. 6 may be attributed to the deviations in the ignition delay time correlation reported in Section 3 of this work. These deviations can be reduced further if the correlation coefficients are optimized over smaller windows of pressure, temperature, equivalence ratio and compositions which are relevant to the specific working conditions of the selected engine. Nevertheless, the results reported here show that the developed IDT correlation could be used effectively to predict combustion phasing in practical combustion engine simulations. These can be very useful to quickly screen out various geometrical and physical parameters to optimize modern engines without the need to solve complex chemistry. 
Red: Main heat release

Black: Low-T heat release
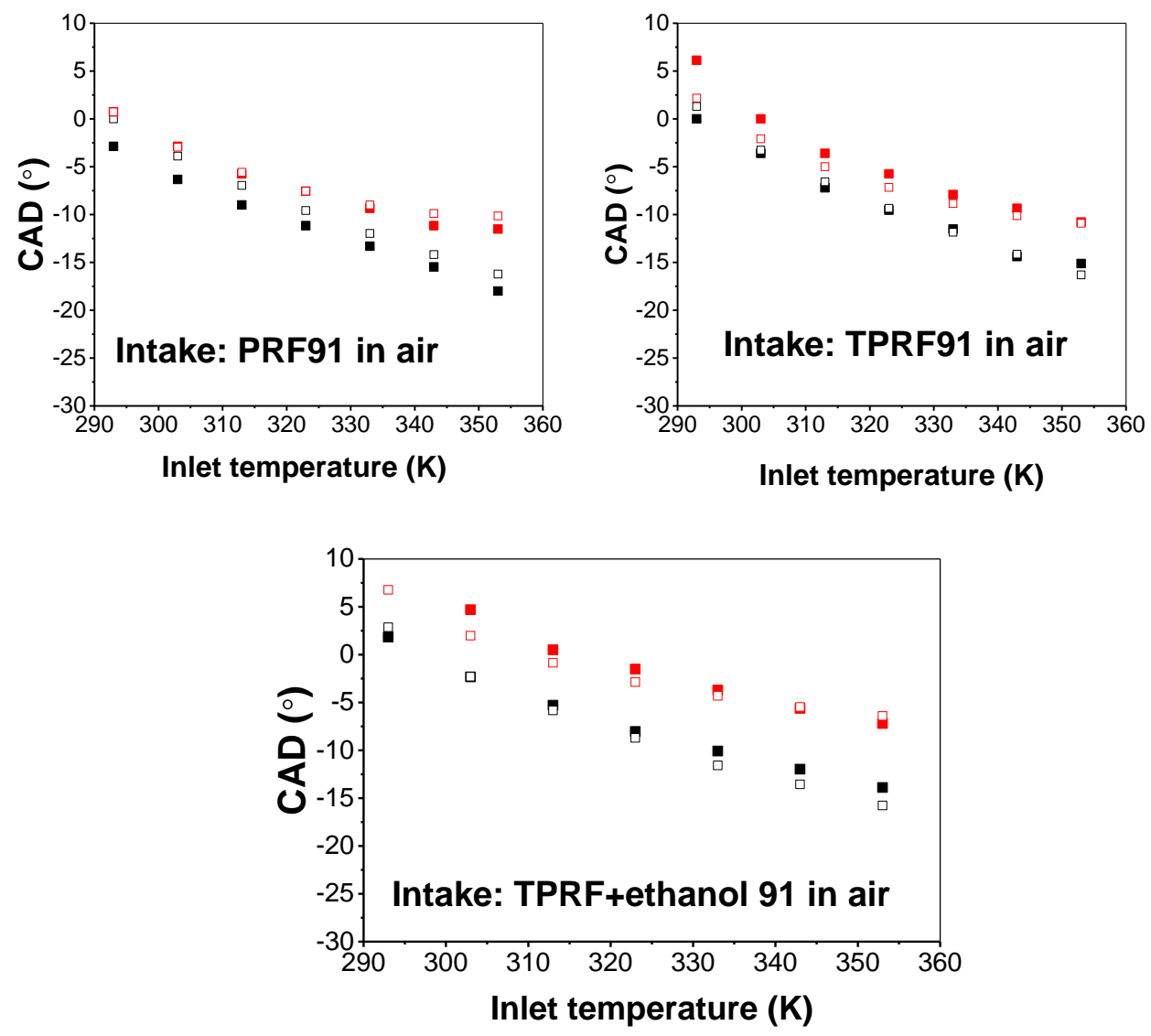

Figure 6 : Crank angle timing of the peak of low-temperature heat release and main heat release rates as a function of inlet temperature. Camparison between HCCI simulations (solid symbols) and predictions using the correlation developed in this work (hollow symbols). The mixture compositions are given in Table 4.

\section{Conclusions}

A new correlation scheme is proposed in this work to predict ignition delay times (IDTs) of fuel blends from the IDTs of pure components with the inclusion of chemical interaction parameters. The proposed formulation is based on the Livengood-Wu integral and we have provided some new insights on the applicability of this integral. Various literature formulations are described and it is suggested that the cool flame description of Yates et al. [26] is suitable for single-component fuels containing NTC region. The methodology proposed in this work for fuel blends is tested against 
simulated ignition delay times of mixtures of iso-octane, n-heptane, toluene and ethanol. We believe that this methodology is quite universal and that it can be applied for any mixtures of fuels over wide ranges of thermodynamic conditions with overall uncertainty bounds of as low as $10 \%$. The developed correlation, however, is dependent on the specific kinetic mechanism used to derive the correlation parameters. The outputs of this study could be applied in advanced engine simulations to predict combustion phasing and heat release patterns for optimization of engine design.

\section{Acknowledgments:}

Work reported in this publication was funded by Saudi Aramco under the FUELCOM program and by King Abdullah University of Science and Technology (KAUST). 


\section{REFERENCES}

1. G. Kalghatgi; K. Morganti; I. Algunaibet; M. Sarathy; R. Dibble, in: SAE International: 2016.

2. G. Kalghatgi; H. Babiker; J. Badra, (2015).

3. T. W. Ryan, in: SAE International: 1985.

4. $\quad$ K. J. Morganti; T. M. Foong; M. J. Brear; G. da Silva; Y. Yang; F. L. Dryer, Fuel 108 (0) (2013) 797811.

5. J. A. Badra; N. Bokhumseen; N. Mulla; S. M. Sarathy; A. Farooq; G. Kalghatgi; P. Gaillard, Fuel 160 (2015) 458-469.

6. E. Singh; J. Badra; M. Mehl; S. M. Sarathy, Energy Fuels Accepted (2017).

7. $\quad$ N. Naser; S. Y. Yang; G. Kalghatgi; S. H. Chung, Fuel 187 (2017) 117-127.

8. W. R. Leppard, in: SAE Technical Paper: 1990.

9. H. J. Curran; P. Gaffuri; W. J. Pitz; C. K. Westbrook; W. R. Leppard in: Autoignition chemistry in a motored engine: an experimental and kinetic modeling study, Symp. (Int.) Combust., 1996; Elsevier: 1996; pp 2669-2677.

10. M. Mehl; T. Faravelli; F. Giavazzi; E. Ranzi; P. Scorletti; A. Tardani; D. Terna, Energy Fuels 20 (6) (2006) 2391-2398.

11. M. Hori; H. Nakamura; T. Tezuka; S. Hasegawa; K. Maruta, Proc. Combust.Inst 34 (2) (2013) 34193426.

12. M. Hori; A. Yamamoto; H. Nakamura; T. Tezuka; S. Hasegawa; K. Maruta, Combust. Flame 159 (3) (2012) 959-967.

13. M. Mehl; W. J. Pitz; C. K. Westbrook; H. J. Curran, Proc. Combust.Inst 33 (1) (2011) 193-200.

14. S. M. Sarathy; T. Javed; F. Karsenty; A. Heufer; W. Wang; S. Park; A. Elwardany, et al., Combust. Flame 161 (6) (2014) 1444-1459.

15. B. Akih-Kumgeh; J. M. Bergthorson, Energy Fuels 27 (4) (2013) 2316-2326.

16. J. A. Badra; J. Sim; A. Elwardany; M. Jaasim; Y. Viollet; J. Chang; A. Amer, et al., Journal of Energy Resources Technology 138 (5) (2016) 052202.

17. J. Badra; Y. Viollet; A. Elwardany; H. G. Im; J. Chang, Applied Energy 183 (2016) 1197-1208.

18. J. Badra; A. Elwardany; J. Sim; Y. Viollet; H. Im; J. Chang, in: SAE Technical Paper: 2016.

19. J. Pan; P. Zhao; C. K. Law; H. Wei, Int. J. Engine Res. (2015).

20. J. C. Livengood; P. C. Wu, Symp. (Int.) Combust. 5 (1) (1955) 347-356.

21. J. J. Hernández; J. Sanz-Argent; J. M. Carot; J. M. Jabaloyes, Int. J. Engine Res. 11 (3) (2010) 199206.

22. N. A. Henein; J. A. Bolt, in: SAE International: 1969.

23. S. S. Goldsborough, Combust. Flame 156 (6) (2009) 1248-1262.

24. D. N. Assanis; Z. S. Filipi; S. B. Fiveland; M. Syrimis, J. Eng. Gas Turbines Power 125 (2) (2003) 450457.

25. A. Lifshitz; K. Scheller; A. Burcat; G. B. Skinner, Combust. Flame 16 (3) (1971) 311-321.

26. A. D. B. Yates; C. L. Viljoen, in: SAE International: 2008.

27. J. Ma; K. H. Kwak; B. Lee; D. Jung, Fuel 164 (2016) 305-313.

28. A. Lifshitz, in: Handbook of Shock Waves, G. Ben-Dor; O. Igra; T. Elperin, (Eds.) Academic Press: San Diego, 2001; Vol. 3.

29. B. P. Mullins, Studies on the spontaneous ignition of fuels injected into a hot air stream. Part II. The effect of physical factors upon the ignition delay of Kerosine-air mixtures, Ministry of Aviation, 1951. 30. R. E. Miller, Symp. (Int.) Combust. 7 (1) (1958) 417-424.

31. G. Ben-Dor; O. Igra; T. Elperin, Handbook of Shock Waves, Three Volume Set, Elsevier Science, 2000.

32. D. F. Davidson; R. K. Hanson, Int. J. Chem. Kinet. 36 (9) (2004) 510-523. 
33. H. J. Curran; P. Gaffuri; W. J. Pitz; C. K. Westbrook, Combust. Flame 129 (3) (2002) 253-280.

34. H. J. Curran; P. Gaffuri; W. J. Pitz; C. K. Westbrook, Combust. Flame 114 (1-2) (1998) 149-177.

35. G. A. Weisser. Modelling of combustion and nitric oxide formation for medium-speed DI diesel engines, a comparative evaluation of zero- and three-dimensional approaches. Universität (TH) Karlsruhe, 2001.

36. C. K. Blomberg; D. Mitakos; M. Bardi; K. Boulouchos; Y. M. Wright; A. Vandersickel, SAE International Journal of Engines 9 (2016-01-0755) (2016).

37. K. Steurs; C. Blomberg; K. Boulouchos, (2014).

38. A. Vandersickel. Two approaches to auto-ignition modelling for $\mathrm{HCCl}$ applications. Eidgenössische Technische Hochschule ETH Zürich, 2011.

39. A. Yates; A. Bell; A. Swarts, Fuel 89 (1) (2010) 83-93.

40. H. Ando; Y. Ohta; K. Kuwahara; Y. Sakai, Rev. Automot. Eng. 30 (4) (2009) 363-370.

41. M. Nose; M. Furutani; T. Sugimoto; Y. Ohta, Trans. Jpn. Soc. Mech. Eng., B 67 (661) (2001) 23262332.

42. M. Nose; Y. Ohta; M. Furutani; T. Isogai, Trans. Soc. Automot. Eng. Jpn. 32 (2) (2001) 11-18.

43. S. M. Sarathy; G. Kukkadapu; M. Mehl; T. Javed; A. Ahmed; N. Naser; A. Tekawade, et al., Combust. Flame 169 (2016) 171-193.

44. I. Reaction Design, in: CHEMKIN PRO Release 15101 ed.; San Diego, CA, 2010.

45. A. S. AlRamadan; S. M. Sarathy; M. Khurshid; J. Badra, Fuel 180 (2016) 175-186. 


\section{APPENDIX}

SECTION A: INTEGRATION TIME AND LIVENGOOD-WU INTEGRAL

We want to prove that under relevant engine conditions:

$$
\frac{d\left(h\left(\frac{x}{x_{c}}\right)\right)}{d t}=\frac{1}{\tau}
$$

where:

$$
h\left(\frac{x}{x_{c}}\right)=\frac{t}{\tau}
$$

Differentiating, we get:

$$
\frac{d\left(h\left(\frac{x}{x_{c}}\right)\right)}{d t}=\frac{d\left(\frac{t}{\tau}\right)}{d t}=\frac{1}{\tau}-\frac{t}{\tau^{2}} \frac{d \tau}{d t}
$$

We know that the ignition delay time is a function of pressure and temperature. In differential form, this can be written as following:

$$
\frac{d \tau}{d t}=\frac{\partial \tau}{\partial T} \cdot \frac{d T}{d t}+\frac{\partial \tau}{\partial P} \cdot \frac{d P}{d t}
$$

Using the expression in Eq. (1) of the manuscript, we can write:

$\frac{\partial \tau}{\partial T} \cong-\frac{E}{R} \cdot \frac{1}{T^{2}} \cdot \tau \quad$ and $\quad \frac{\partial \tau}{\partial P} \cong \frac{n}{P} \cdot \tau$,

Then:

$$
\frac{d \tau}{d t}=\tau \cdot\left(\frac{E}{R} \cdot \frac{1}{T^{2}} \cdot \frac{d T}{d t}+\frac{n}{P} \cdot \frac{d P}{d t}\right)
$$

Typical value for $\mathrm{E} / \mathrm{R}$ is $-20000 \mathrm{~K}, \mathrm{n}$ is -0.7 (values taken from high T IDT of iso-octane and $\mathrm{n}$-heptane) and for relevant engine operating conditions $\mathrm{dT} / \mathrm{dt}$ is about $180 \mathrm{~K} / \mathrm{ms}$ and $\mathrm{dP} / \mathrm{dt}$ is about $1.25 \mathrm{bar} / \mathrm{ms}$. Thus:

$$
\frac{d \tau}{d t} \cong-10000 \tau
$$

Then we finally get:

$\frac{d\left(h\left(\frac{x}{x_{c}}\right)\right)}{d t}=\frac{1}{\tau}-\frac{1000 . t}{\tau}=\frac{1}{\tau}(1+10000 . t)$

If the previous integral is calculated over a time scale of $100 \mu$ s, then the second term becomes 0.01 which is small enough to be considered negligible as long as the Livengood-Wu integral is calculated over small time intervals. 
In general, a critical time scale can be derived for the L-W integral that can be written in the form:

$$
\varepsilon=\frac{1}{\left|\frac{E}{R} \cdot \frac{1}{T^{2}} \cdot \frac{d T}{d t}\right|_{\max }+\left.\frac{n}{P} \cdot \frac{d P}{d t}\right|_{\max } \mid}
$$

While calculating ignition delay times of a real T-P process using the L-W integral, one has to make sure that the time interval of the integral is small enough compared to the critical time scale $\varepsilon$.

\section{SECTION B: L-W INTEGRAL FOR NTH ORDER OF KINETICS:}

We want to prove that the Livengood-Wu integral is valid for any global order of kinetics.

The order of kinetics, $n$, can be written as:

$$
\frac{d\left[\frac{x}{x_{c}}\right]}{d t}=\text { const. }\left[\frac{x}{x_{c}}\right]^{n}
$$

We can then write:

$$
\frac{d\left(\left(\left[\frac{x}{x_{c}}\right]\right)^{1-n}\right)}{d t}=(1-n) \cdot\left[\frac{x}{x_{c}}\right]^{-n} \cdot \frac{d\left[\frac{x}{x_{c}}\right]}{d t}=\text { const } \cdot(1-n)
$$

Thus:

$$
\left[\frac{x}{x_{c}}\right]^{1-n}=\int_{t=0}^{t} \text { const. }(1-n) \cdot d t
$$

At ignition, $x$ reaches its critical value $x_{c}$, then this integral becomes 1 and we have: $1=$ const. $\tau .(1-n)$

We conclude then:

$$
\left[\frac{x}{x_{c}}\right]^{1-n}=\int_{0}^{t} \frac{1}{\tau} \cdot d t
$$

And at ignition, we recover the L-W integral:

$$
1=\int_{0}^{t_{i g n}} \frac{1}{\tau} \cdot d t
$$




\section{SECTION C: TEST OF THE LIVENGOOD-WU INTEGRAL}

As a proof-of-concept and to further demonstrate the performance of the Livengood-Wu integral, zero dimensional IDT simulations are performed using the detailed chemical kinetic model of primary reference fuels (n-heptane, iso-octane) [1] and these simulated IDTs are compared against those calculated with L-W integral approach. Stoichiometric n-heptane/air (3.76/1 N2/O2) mixture at a pressure of $10 \mathrm{~atm}$ was considered for this comparison. A stepwise $T-P$ process is chosen as a validation case where $P$ is unchanged and $T$ is increased by $10 \%$ of its initial value halfway between the start of simulation and ignition (see inset of Fig. 1). The ignition delay time of this process according to the Livengood-Wu integral is given by:

$$
\begin{gathered}
\tau_{\text {ign }}\left(T_{0}, P_{0}\right)=\tau\left(1.1 T_{0}, P_{0}\right)+\frac{\tau\left(T_{0}, P_{0}\right)}{2} \cdot\left(1-\frac{\tau\left(1.1 T_{0}, P_{0}\right)}{\tau\left(T_{0}, P_{0}\right)}\right) \\
=\frac{\left(\tau\left(1.1 T_{0}, P_{0}\right)+\tau\left(T_{0}, P_{0}\right)\right)}{2}
\end{gathered}
$$

where $\tau\left(T_{0}, P_{0}\right)$ (or $\tau\left(1.1 T_{0}, P_{0}\right)$ ) is the typical constant $\mathrm{U}-\mathrm{V}$ ignition delay time at initial pressure of $\mathrm{P}_{0}$ and temperature $\mathrm{T}_{0}$ (or $1.1 \mathrm{~T}_{0}$ ). A comparison between the simulated and calculated IDTs using Eq. (1) is shown in Fig. 1, where an excellent agreement is observed.

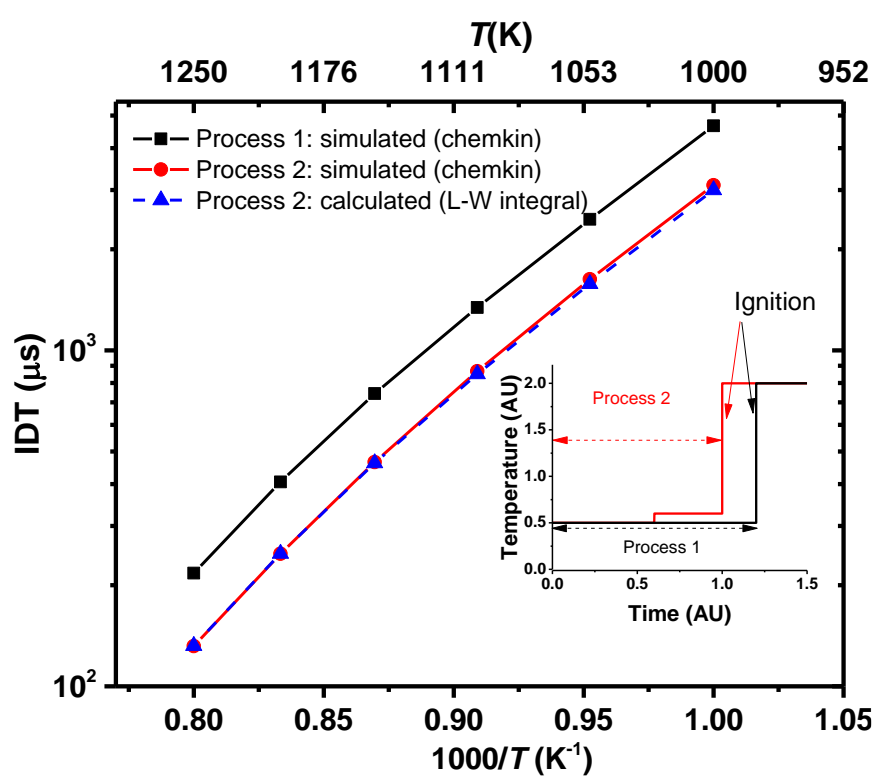

Figure 1: Ignition delay times of of $n$-heptane at $\mathrm{P}=10$ atm and $\phi=1$ : Comparison between Chemkin simulations and L-W integral calculations. Process 1 is a constant T, P process whereas process 2 is a constant $\mathrm{P}$, staged $\mathrm{T}$ process, as shown in the inset. 
Simulations were performed using the Chemkin-Pro [2] software where the continuation option was used to create a constant volume simulation with a stepwise T-P profile. Comparing the black and the red lines in Fig. 1, it is concluded that the imposed rise of temperature in process 2 resulted in a reduction of the ignition delay time as compared to the constant UV case (process 1). A similar behavior is seen at intermediate temperatures for some hydrocarbons where a cool flame temperature and pressure rises increases the reactivity of fuels. This region of the Arrhenius plot of ignition delay time is called the negative temperature coefficient (NTC) region (see Fig. 1 of the paper). Experimental and theoretical evidences show that the NTC region is correlated to the cool flame phenomena [3-5]. The cool flame causes a sudden rise in pressure and temperature before the main ignition event and this process is known as the two-stage ignition [6]. These observations led many authors to solely explain the NTC region by coupling the cool flame $T$-P rise to the L-W integral [3, 4]. For example, the correlation of Yates et al. [4] describes the NTC region of n-heptane and iso-octane using information on the high-temperature ignition delay time, the first stage ignition and the cool flame temperature and pressure rises. Yates et al. [4] successfully applied their methodology to describe ignition delay times of n-heptane and isooctane and in this paper we adopted this methodology for single component fuels IDT correlation.

1. H. J. Curran; W. J. Pitz; C. K. Westbrook; G. V. Callahan; F. L. Dryer,Oxidation of automotive primary reference fuels at elevated pressures Symp. (Int.) Combust. 27 (1) (1998) 379-387.

2. I. Reaction Design, in: CHEMKIN PRO Release 15101 ed.; San Diego, CA, 2010.

3. J. Pan; P. Zhao; C. K. Law; H. Wei,A predictive Livengood-Wu correlation for two-stage ignition Int. J. Engine Res. (2015).

4. A. D. B. Yates; C. L. Viljoen, An Improved Empirical Model for Describing Auto-ignitionin: SAE International: 2008-01-1629, 2008.

5. $\quad$ S. Y. Mohamed; L. Cai; F. Khaled; C. Banyon; Z. Wang; M. J. Al Rashidi; H. Pitsch, et al.,Modeling Ignition of a Heptane Isomer: Improved Thermodynamics, Reaction Pathways, Kinetics, and Rate Rule Optimizations for 2-Methylhexane J. Phys. Chem. A 120 (14) (2016) 2201-2217.

6. M. P. Halstead; A. Prothero; C. P. Quinn,A Mathematical Model of the Cool-Flame Oxidation of Acetaldehyde Proceedings of the Royal Society of London A: Mathematical, Physical and Engineering Sciences 322 (1550) (1971) 377-403. 